\title{
La Excepcionalidad del Otro
}

\section{The Exceptionality of the Other}

\author{
Simone Belli; Cristian López; Javier Romano \\ Universidad Autónoma de Barcelona \\ simone.belli@uab.es \\ cristian.lopezr@campus.uab.es \\ javierenrique.romano@campus.uab.es
}

\begin{abstract}
Resumen
Abstract

Esta artículo es un viaje por un archipiélago conceptual, This paper is a voyage in an archipelago of concepts, a una práctica de nomadismo, una invitación a pensar nomadic journey, and an invitation to think about the sobre el otro, sobre lo social y el imaginario. Nuestro other and about the social and the imaginary. Our objetivo es desandar caminos, cuestionar verdades, objective is to step back, to question "truths", and to obstaculizar la producción de conocimiento totalizante y reject the production of absolute knowledge; and by depredador, en suma, propiciar la emergencia de doing so, to stimulate doubts and suspicions about the intercambios, dudas y sospechas para con la production of scientific knowledge and its effects on the producción de conocimiento científico y sus efectos en social imaginary. el imaginario social de la alteridad.
\end{abstract}

Palabras clave: Alteridad, conocimiento, imaginario Keywords: Alterity, Knowledge, Social Imaginary social

\section{Presentación}

El presente artículo nace de la confrontación de las ideas presentes en nuestras investigaciones y guarda una relación directa con las temáticas que llevamos a cabo en nuestras diferentes trayectorias formativas y profesionales. Nos disponemos a propiciar una reflexión acerca de la construcción social de la alteridad y el agiornamiento del concepto de imaginario social desde una mirada interdisciplinar y crítica. Entendemos como mirada interdisciplinar esas diferentes formas de organización del mundo que cada mirada [disciplinar] implica, al igual que entendemos la crítica como esa forma de ejercer el pensamiento que no intenta reducirlo todo al diálogo ni a la comprensión sentimental o analítica, sino que aboga por recuperar la extrañeza y la multiplicidad del mundo. Al enfoque psicosocial agregamos aquellas miradas que bien se pueden identificar con un interés de tipo epistemológico u ontológico y que consideramos imprescindibles en el debate actual dentro de las Ciencias Sociales.

Es desde esta multiplicidad de voces e incertidumbres, donde nuestra reflexión encuentra sentido y profundidad; frente a la complejidad de los problemas, las mediaciones de las instituciones, los límites ideológicos, metodológicos y la exigencia de resultados verificables nuestra propuesta intenta ser una 
pausa sin otro atributo que la intención de mirar, narrar y fabular sobre los efectos que ciertos discursos generan sobre nuestros (Otros) cuerpos y signos compartidos (Imaginario).

Presentamos, y construimos, el Otro de tres formas distintas, complementarias y "genuinas". En la primera parte se tratará de descubrir el imaginario social de lo otro, para poderlo manejar y preparar así el equipaje para partir. Pero un viaje no solo está hecho de palabras, de narraciones, sino también de imágenes del Otro, que también nos hacen pensar. Esto no significa poner imágenes a las palabras y texto a las miradas, sino pensar a través del texto y las imágenes. Ver cuál es ese camino que tanto unas como otras nos hacen seguir.

Será la curiosidad quien nos motivará para viajar juntos por este camino. La curiosidad del encuentro con el Otro, de la búsqueda del Otro y nada más que ella. Es nuestra amiga, porque confiamos en ella y al mismo tiempo es nuestra guía, y la que nos somete, nos obliga a buscar al Otro, es una obligación que tenemos que cumplir. Ella nos motiva y da las fuerzas necesarias para cumplir nuestro viaje. Ella es la causa y el efecto, la que nos permite al mismo tiempo salvar al Otro y salvarnos a nosotros mismos. Así que dedicaremos a ella la segunda parte de este artículo.

¿Pero toda esta curiosidad en la búsqueda del Otro adónde nos lleva? ¿Es correcto y pertinente realizar nuestro viaje sólo para buscar el Otro? ¿No será la búsqueda de algo más profundo que el Otro? Estas tres preguntas son las que fundamentan y articulan nuestra tercera parte. Partimos de la hipótesis que el Otro que hemos encontrado, visto y conocido se ha saturado. Que el Otro pueda estar cansado de todas estas visitas y acercamientos, así que probaremos a ver qué hay más allá de esta búsqueda, de este viaje.

Que cada viaje termina es obvio, pero hay algunos que vuelven a empezar, aunque ya no en el mismo lugar donde empezaron por primera vez sino algunos metros más adelante, o atrás. También puede ser que algunas veces empiecen en el mismo sitio y con los mismos compañeros, pero siempre con una experiencia más rugosa, como la corteza de los árboles con el paso del tiempo. Así que ustedes, queridos lectores, una vez llegado el final de este artículo, tendrán que empezar de nuevo, tendrán que cumplir ese viaje elíptico, eterno y abierto. Todos seremos un poco más viajeros, pero también más próximos a todos nuestros Otros.

\section{Imaginario social y la mirada hacia el Otro}

Situar conceptos tan dispares entre si como lo otro, el Otro, la Alteridad, e incluso, la misma noción de imaginario social nos plantea un primer obstáculo, ya que sus simientes teóricas, metodológicas e históricas son heterogéneas y bajo ningún aspecto consensuadas. Esta situación nos obliga a transitar por un derrotero común a través del cual navegaremos en busca de ese archipiélago de islas donde estos conceptos se materializan.

El término imaginario surge en el siglo XIX como un dominio del Espíritu desdeñado por la razón a la vez que íntimamente ligado a la imaginación como facultad psicológica de engendrar y utilizar imágenes. A mediados del siglo XX con el declinar de una cierta concepción de la Psicología y bajo la presión de las Ciencias Humanas la concepción de la imaginación fue suplantada por el problema del imaginario: un estudio de las producciones de imágenes, sus propiedades y sus efectos (Wunenburger, 2003: 5). 
Con esta concepción de imaginario podemos situarnos dentro de uno de esos problemas no resueltos de la epistemología que planteamos en el inicio de este artículo. Lo imaginario se rechaza por parte de la razón como parte todavía ligada a las concepciones pre-científicas, las creencias religiosas, las producciones artísticas que se sirven de esas facultades imaginarias para inventar otras realidades no necesariamente ligadas al mundo físico. Obviamente esta visión estricta que la llustración lanzó sobre el término imaginario era poco sostenible dentro del abordaje de las Ciencias Sociales, así que fue necesaria su laxitud para poder operativizar aquello que se compartía como común. No la realidad, sino sus imágenes.

Pero el concepto de imaginario es mucho más escurridizo de lo que puede parecer si lo relacionamos con la imagen. Implica mucho más de lo que a simple vista puede ser una variable interviniente en el análisis sociológico. El análisis de la imagen en Ciencias Sociales es uno de esos límites de los que alertábamos al principio de este artículo, uno de esos problemas epistemológicos que aun no se han resuelto. Hasta ahora se ha relegado a la imagen, en sus diferentes modalidades como la fotografía, el cine o la pintura a un análisis compartimentado de conocimientos técnicos o estéticos. Está muy extendida la opinión de que si a uno le interesa lo visual, su interés ha de limitarse a una técnica de tratar lo visual. Así, se establecen categorías de interés especial: pintura, fotografía, apariencias reales, sueños y muchas otras cosas más. Y lo que se olvida -como todas las cuestiones esenciales en una cultura positivista- es el significado y el enigma de la propia visualidad (Berger, 1980: 47).

Ese enigma del que nos habla John Berger nos sitúa en ese conflicto existente entre la positividad de las Ciencias Sociales y sus límites. El ejemplo más claro es el que representa la fotografía y su uso en las ciencias sociales. La idea fundamental es que la fotografía es una estrategia para el conocimiento de la realidad social. Es una ciencia blanda, artística, lábil, pero con un soporte nítido, duro, electrónico y químico (De Miguel y Ponce de León, 1998: 92). La Sociología y la Antropología han utilizado la fotografía como soporte para sus análisis textuales sin atender a las posibilidades textuales de la misma fotografía. Al fin y al cabo, no es de extrañar que la fotografía entre en escena cuando las Ciencias Sociales buscan medios para capturar objetivamente la realidad social. El reto fundamental es el de combinar foto y texto en la investigación (De Miguel y Ponce de León, 1998: 95). Pero esta perspectiva nos induce a pensar a la fotografía como un documento archivado, un soporte físico donde poder acudir para ratificar nuestras impresiones visuales de la realidad cuando lo que la fotografía muestra no es más que un juego de luces sobre un soporte químico. La mirada es mucho más que una simple representación, conlleva una organización del mundo, de lo visible que es previo a la realización de la fotografía (de ahí su encuadre, localización y disparo) y posterior (la medida de su impacto en el imaginario más allá de la representación) ese punctum del que hablaba Barthes (1989).

Esto nos lleva a la pregunta sobre qué hacía las veces de la fotografía antes de su invención allá por el 1822. La respuesta que uno espera es: el grabado, el dibujo, la pintura. Pero la respuesta más reveladora sería: la memoria. Lo que hacen las fotografías allí fuera en el espacio exterior a nosotros, se realizaba anteriormente en la interioridad del pensamiento (Berger, 1980: 56).

Así que nos desplazamos de ese soporte físico de la fotografía para adentrarnos en la memoria, lugar mucho más cercano al imaginario que el del análisis estético de las imágenes. No obstante, a diferencia de la memoria, las fotografías no conservan en sí mismas significado alguno. Ofrecen unas apariencias -con toda la credibilidad y gravedad que normalmente les prestamos- privadas de significado. El significado es el resultado de comprender las funciones. "Y las funciones tienen lugar en el tiempo y han de explicarse en el tiempo. Sólo lo que es capaz de narrar puede hacernos 
comprender". Las fotografías no narran nada por sí mismas. Las fotografías conservan las apariencias instantáneas (Berger, 1980: 57). Si las fotografías no son capaces de narrar nada por sí mismas es porque se las ha tratado como mero reflejo de la realidad, a veces más reales que la misma realidad ya que son capaces de llegar más lejos que el ojo humano, pero sin significado propio y fuera de ese enigma al cual nos lleva cualquier narración.

Esta trayectoria que reseñamos es una señal más que debemos codificar para poder seguir pensando qué es eso del imaginario social y lo que implica esa misma concepción para no perdernos en este archipiélago simbólico. Parece necesario hacer una breve nota sobre el significado que en griego tiene la palabra simbólico para aclarar el tipo de idea que intentamos introducir. En griego, el antónimo exacto de símbolo es el diablo: el que separa. Dia-bólico es todo lo que divide, sin-bólico todo lo que acerca (Debray, 1994: 52). Ese archipiélago simbólico del que hablamos no supone necesariamente una fragmentación de saberes, sino muy al contrario todo lo que acerca a esos saberes entre sí.

Cuando planteamos el problema epistemológico de la representación visual estamos hablando de volver a rehabilitar lo que nos acerca, es decir, poner en duda esa relación con la representación visual del otro sin relegarlo a su sola representación mimética. Hablamos de cómo poder mirar al Otro y entender por qué vemos al Otro y no a nosotros mismos, cuál es esa forma de organizar lo visual que nos lleva a mirar hoy al mundo en tiempo real sin ver nada.

Norbert Elías, a lo largo de su obra, nos advierte reiteradamente de la amenaza que pesa sobre nosotros, sobre nuestra humanidad consistente en que nos acabemos perdiendo en la espesura de nuestros propios símbolos, en la univocidad de nuestras palabras; en que acabemos considerando como naturales, incuestionables, consubstanciales o inevitables las particulares formas de coacción y autodisciplina que nosotros instituimos a través de los específicos e históricos medios de significación y regulación de nuestras vinculaciones e interdependencias (Elías, 1984: 37).

En resumidas cuentas, que la operativización de un concepto como imaginario no puede significar abandonar la reflexión sobre él mismo. Este análisis nos hace de puente para saltar a otra de esas islas del archipiélago donde los conceptos toman forma y sentido, la de los Otros.

El Otro es, quizás, lo que siempre ha apasionado a nuestra cultura. No tanto por la posibilidad de verse a sí misma en estados anteriores y más primitivos, como podían pensar los antropólogos de la época clásica o los defensores del darwinismo social, sino como esa fascinación por lo Otro. La creencia de que estaban delante de cosas extrañas e incomprensibles pero que a la vez podían ser descifradas en clave propia. Ese exotismo radical del que hablaba Víctor Segalen (1995), ese shock primitivo entre culturas.

¿Por qué es importante el Otro en nuestro análisis? ¿Por qué la Alteridad es sujeto de nuestra mirada? Para responder a estas interrogantes podemos hacer nuestra la explicación que da Michel Mafessoli cuando señala: Se puede decir que es a partir de la concepción que se forma una época de la Alteridad, como puede determinarse la forma esencial de una determinada sociedad (Mafessoli, 1990: 157)

Ante todo nos preguntarnos por qué vagamos de isla en isla buscando al Otro, será tal vez que esta búsqueda del Otro se produce a partir de nuestra propia forma de construir la Alteridad. ¿Por qué estamos buscando desesperadamente esa diferencia que ya encontramos en tierra firme? 


\section{La curiosidad en la búsqueda del Otro}

A propósito de la búsqueda del Otro, es oportuno que hagamos referencia al concepto de curiosidad que utiliza Heidegger y que comenta Virno (2003). Citando a Agustín de Hipona (Confesiones, Libro $\mathrm{X}$, cap.35), Heidegger define al curioso como aquel que se abandona a la concupiscentia oculorum, a la concupiscencia de la vista, ansioso por asistir a espectáculos insólitos e incluso horribles. La curiosidad quiere tener la experiencia, sobre todo en la búsqueda del Otro, el placer que provoca su búsqueda, incluso si el Otro se transforma en la horrible visión de un cadáver despezado (Virno, 2003). Sin embargo, si hay uno en alguna parte, todos acuden allí, o delante de una pantalla plana para ver el telediario de la noche.

Según Heidegger, la curiosidad busca el Otro nuevo exclusivamente como trampolín de lanzamiento hacia otro nuevo, demostrando una incapacidad típica de detenerse sobre lo que se presenta. Es una continua búsqueda, incesante y extenuante, que acaba en la derrota y en el fracaso del Yo. Como se vera en los próximos párrafos, no estamos salvando lo Otro, sino a lo Mismo.

Michael Billig (1988) ha estudiado los valores, objetivos e ideales que asume la gente en su relación con el Otro en la vida cotidiana. Comprobó que lo normal es que el individuo sufra un conflicto interno. Las personas piensan que sus prejuicios están justificados, pero consideran negativo ser intolerantes, racistas o xenófobos. Es esta dualidad que permanece en la relación con el Otro. Billig afirma que la capacidad para la contradicción es esencial ante las demandas prácticas que impone la vida en las relaciones con el Otro.

Nos enfrentamos a un orden, o un desorden del mundo en el que existiría originariamente una coexistencia antagonista de dos principios eternos, el bien y el mal, una dualidad perversa de ver la Alteridad. Esta dualidad perversa, según Baudrillard (2002), hace que todos los intentos de hacer el bien conduzcan, a medio o a largo plazo, al mal. Pero también, en cualquier caso, esta dualidad es el autentico origen de cualquier energía, sin que eso signifique pontificar acerca del principio, bien o mal, originario (Baudrillard, 2002).

No es posible concebir un sistema de valores que pretenda funcionar al unísono en todas las culturas. Este hecho sería paradójico y contradictorio ya que no podría pensarse con cierta dosis de relativismo y simultáneamente como un marco general que superaría a todos los sistemas de valores que le anteceden. No nos imaginamos que lo universal puede ser tan sólo el pensamiento particular de Occidente, su producto específico, sin duda original, pero tampoco exportable a la postre como cualquier producto genuino (Baudrillard, 2000: 79).

Entonces, no podemos pensar esta Alteridad como nuestra, en el sentido comparativo de la palabra. Creemos que puede existir esa forma de construir la Alteridad en el resto de culturas, pero quizás no vemos que sólo nosotros hemos pretendido tener la última palabra. Esto conlleva varios peligros, entre ellos, lo que podríamos llamar el melodrama de la diferencia. De repente, el Otro ya no está hecho para ser exterminado, odiado, rechazado, seducido, está hecho para ser entendido, liberado, mimado, reconocido. Después de los Derechos del Hombre, habría que instituir los Derechos del Otro. Ya existen, por otra parte: es el Derecho Universal a la Diferencia. Orgía de comprensión política y psicológica del Otro, resurrección del Otro allí donde ya no existe. Allí donde estaba el Otro, ha aparecido el Mismo (Baudrillard, 1991: 135). 
No estamos salvando lo Otro, sino a lo Mismo. Es la última oportunidad de nuestra cultura para no perderse en la universalidad de sus valores. No decimos nada nuevo cuando afirmamos que cualquier sistema de valores que se universaliza pierde su singularidad y desaparece. Así sólo nos queda la posibilidad de mantener viva la diferencia, aunque sea a costa de la singularidad de los Otros. Salvándola a ella nos salvamos nosotros o, como mínimo, eso creemos.

\section{El Otro saturado}

Hace cien años las relaciones con el Otro se circunscribían básicamente al perímetro de las distancias que podían recorrerse sin cansancio, como explica Gergen (1992). El Otro era constituido por los elementos de la familia, del vecindario y del pueblo donde uno residía. Con la llegada de las nuevas tecnologías, el Otro se ha hecho mucho más numeroso y frecuente. La vida contemporánea es un mar turbulento de relaciones sociales (Gergen, 1992). Los cambios producidos por el modo de producción capitalista y el desarrollo tecnológico provocaron un aumento y variedad de las relaciones que entablamos con el Otro, la frecuencia potencial de la Alteridad, la intensidad expresada en dichas relaciones y su duración. Esto es tan así que se puede llegar a una saturación del Otro. Esta saturación permite que las diferencias del Otro sean banalizadas y anuladas. La cantidad de relaciones con el Otro, crean un Otro común, normalizado, donde las diferencias entre sí, llegan a ser estereotipadas y de naturaleza racista. La saturación social del Otro contribuye a una escisión multifrénica del individuo en miles de relaciones fragmentarias.

No existe una buena utilización de la diferencia. Es algo que revela no sólo el racismo, sino todos los esfuerzos antirracistas y humanitarios de promoción y protección de la diferencia. En todas partes, el ecumenismo humanitario, el ecumenismo de la diferencia, se encuentra en un absoluto atolladero, el mismo del concepto de universal (Baudrillard, 1991: 141). Entonces, esa maquinaria de (re)producción de sentido que es la Alteridad se convierte en una especie de válvula de escape donde Occidente resuelve su carácter indefinido. Se convierte a cualquier diferencia en lo Mismo, ya que el integrismo culturalista se opone a la Alteridad radical. Esto es así por una sencilla razón, la diferencia es un virus infeccioso suministrado por nuestra cultura, y la Alteridad radical es el rechazo absoluto del sistema inmunológico de lo simbólico. La Alteridad radical es la resistencia absoluta a la comunicación, a la posibilidad de entendernos, del consenso y de todas las prácticas totalitarias del pensamiento único que intentan reducir la radicalidad del mundo bajo el manto de la comprensión del Otro. No hay nada que comprender, nada que compartir, en eso reside la fuerza de la Alteridad radical, no puede ser intercambiada como un objeto con(sin) valor.

La Alteridad radical resiste a todo: a la conquista, al racismo, al exterminio, el virus de la diferencia, el psicodrama de la alienación. De una parte, el Otro siempre está muerto; de la otra, es indestructible. Así es el Gran Juego (Baudrillard, 1991: 156). Ni que decir tiene que este es uno de los máximos impedimentos a los que se enfrenta la Sociología y las Ciencias Sociales. Cómo abordar este tipo de análisis que se escapa a las relaciones conjuntista-identitaria de las que nos hablaba Cornelius Castoriadis (1989) cuando intentaba hacer frente al dilema de la creación. La ontología heredada, al estipular la relación de causalidad como modelo de explicación, choca con la imposibilidad de encontrar una respuesta satisfactoria, racional, lógico-científica para lo imaginario. Castoriadis no se cansa de repetirlo: la creación es el paso del no-ser al ser, por tanto, la creación no tiene explicación. 
¿Qué hacer en la vicisitud de seguir conservando la diferencia cuando la Alteridad radical se manifiesta en forma de rechazo absoluto a los valores universales y redentores que Occidente creía haber conseguido introducir en todas las islas del archipiélago?

El Otro radical es insoportable, no se le puede exterminar, pero tampoco se lo puede aceptar: así que hay que promover el Otro negociable, el Otro de la diferencia. Aquí comienza una forma de exterminio más sutil en la que intervienen todas las virtudes humanistas de la modernidad (Baudrillard, 1991: 144). El exterminio es la solución que nuestro sistema de valores ha encontrado siempre que se ha visto amenazado. Pero las formas del exterminio pueden ser muy dispares, incluso nada se pueden parecer a la violencia que históricamente ha ejercido Occidente en lo Otro. Esta vez, la violencia se ejerce a partir de la comprensión, la comunicación y el diálogo con el Otro. Convirtiéndolo en interlocutor se le aparta de ese exotismo radical, de la incomprensibilidad eterna, la extrañeza irreductible de las culturas, de las costumbres, de los rostros, de las lenguas.

Se sitúa al Otro en la misma forma de construir lo Mismo que nosotros para hacer posible su inclusión y reivindicación de su diferencia.

Lo peor es la comprensión, que sólo es una función sentimental e inútil. El auténtico conocimiento es el de que jamás nos comprenderemos en el Otro, lo cual hace que este otro no sea uno mismo y, por consiguiente, no pueda ser separado de sí, ni alienado por nuestra mirada, ni instituido en su identidad o en su diferencia (Baudrillard, 1991: 158). Navegamos en un archipiélago en busca del Otro cuando en realidad nos buscamos a nosotros. Pero el Otro nunca estuvo allí, siempre viajó de polizonte en nuestra barcaza. Lo que encontramos no fue al Otro sino al polizonte que llevábamos, nunca tan extraño como conocido. Porque navegar a la deriva siempre incluye riesgos, y esos riesgos son los que tienen que asumir las Ciencias Sociales.

\section{Un final para volver a empezar}

Desde el nacimiento y legitimación de las Ciencias Sociales como disciplinas científicas el tema de la integración / desviación ha sido una constante histórica que les ha dado poder. Este reflejo denota la preocupación que las distintas culturas han tenido sobre la convivencia, el control, el disciplinamiento y la cohesión social.

La producción de conocimiento sobre este tema ha sido eurocéntrica, la narrativa histórica ha reflejado la visión del conquistador y nunca la del conquistado, la del sujeto activo (cognoscente) sobre el pasivo (objeto de conocimiento).

Con la idea de posmodernidad asociada al fin de los metarelatos el otro comienza a tener un lugar en la historia, surge la idea de discurso débil (Vattimo y Rovatti, 1988) ${ }^{1}$ donde los homosexuales, las mujeres, las minorías étnicas comienzan a tejer su propio entramado histórico de emergencia y convivencia con el resto de la sociedad integrada.

1 Sobre esta categorización de "pensamiento débil" consultar la obra de Gianni Vattimo quien considera que la posmodernidad se caracteriza por un desplazamiento de las verdades totalizantes (y por lo tanto "fuertes") por versiones de las minorías que estarían lejos de las huellas de la historia con mayúscula pero cercanas al "pasar despreocupadas" a cierto "nihilismo débil." 
El crepúsculo de las totalidades épicas no fue sinónimo de liberación de clase o sujeto social alguno, menos aún de integración. Problemas como la xenofobia, la pobreza y el racismo están teniendo un nuevo empuje. Este cambio histórico ha afectado de manera cualitativa a la producción científica, estética e ideológica de nuestra contemporaneidad.

A modo de ejemplo, podemos apreciar como el fundamentalismo cultural con su apuesta por la diversidad cultural es un síntoma paradójico que vincula por un lado, valores éticos comprometidos con el humanismo (respeto, tolerancia, solidaridad, etc.) y por otro, invisibiliza prácticas de segregación, discriminación y rechazo en una misma geografía cultural y simbólica plagada de gestos de recelo hacia la Otredad.

Como se puede apreciar este derrotero que nos propusimos transitar ha ido tocando distintos puertos conceptuales, históricos y disciplinarios, nuestra hoja de ruta se sigue construyendo, abierta a los signos emergentes de nuestro tiempo.

Creemos que abordar este tema desde una perspectiva crítica debe necesariamente dejar puntos en suspenso y preguntas construyéndose junto al lector. Muchas veces la práctica de producción de conocimiento es depredadora y mutiladora; ante esto es vital desandar caminos, cuestionar verdades, proponer escenarios de diálogo e intercambio con los actores involucrados en cada dispositivo de saber / poder.

Como habréis comprendido, queridos lectores, el viaje no concluye aquí. Esta es solo una experiencia más en nuestro/vuestro equipaje de mano. Otros viajes os esperan, otras búsquedas de los Otros tendréis, no os preocupéis: la vida es un continuo viaje enriquecedor donde el Otro siempre nos acompaña, nos obstaculiza o nos mata. Pero esto es parte elemental y constitutiva de la existencia misma.

"Uno abre una pequeña hendidura en el circulo, lo abre del todo, deja entrar a alguien, invita a alguien, o de lo contrario sale uno mismo, se echa a andar. (...) Uno se echa a andar, aventura una improvisación. Pero improvisar es sumarse al Mundo, fusionarse con éste". (Gilles Deleuze y Fèlix Guattari, A Thousand Plateaux, 1987, p.25).

\section{Referencias}

Baudrillard, Jean. (2002). Contraseñas. Barcelona: Anagrama.

Baudrillard, Jean. (1987). Cool Memories. Paris: Galiée.

Baudrillard, Jean. (1991). La transparencia del mal: Ensayo sobre los fenómenos extremos. Barcelona: Anagrama.

Baudrillard, Jean. (2000). Pantalla total. Barcelona: Anagrama.

Barthes, Roland. (1989). La cámara lúcida. Notas sobre la fotografía. Barcelona: Paidós.

Berger, John. (1980). Mirar. Barcelona: Gustavo Gili.

Castoriadis, Cornelius. (1989). La institución imaginaria de la sociedad. Vol. 2. La imaginación social y la institución. Barcelona: Tusquets. 
Debray, Régis. (1994). Vida y muerte de la imagen. Historia de la mirada en Occidente. Barcelona: Paidós.

Deleuze, Gilles y Guattari, Félix. (1987). A Thousand Plateaux. Minneapolis: University of Minnesota Press.

Elías, Norbert. (1984). Sobre el tiempo. México: Fondo de Cultura Económica.

Gergen, Kenneth. (1992). El yo saturado. Barcelona: Paidós.

Mafessoli, Michel. (1990). El tiempo de las tribus. El declive del individualismo en la sociedad de masas. Barcelona: Icaria.

Miguel, Jesús M. y Ponce de León, Omar (1998): Para una sociología de la fotografía. Revista Española de Investigaciones Sociológicas, 84, 83-124.

Segalen, Victor. (1995). Oeuvres complètes. París: Robert Lafont.

Vattimo, Gianni y Rovatti, Pier Aldo. (1988). El pensamiento débil. Madrid: Editorial Cátedra.

Virno, Paolo. (2003). Virtuosismo y revolución. Madrid: Traficantes de Sueños.

Wunenburger, Jean Jacques. (2003). L'imaginaire. París: Presses Universitaires de France.

\section{Historia editorial}

Recibido: 20/03/2007

Primera revisión: 12/04/2007

Aceptado: 29/04/2007

\section{Formato de citación}

Belli, Simona; López, Cristian y Romano, Javier (2007). La Excepcionalidad del Otro. Athenea Digital, 11, 104-113. Disponible en

http://psicologiasocial.uab.es/athenea/index.php/atheneaDigital/article/view/342/328.

Simone Belli: (Bergamo-Italia, 1981) es doctorando en Psicología Social y licenciado en Ciencias de la Educación por la Università degli Studi di Bergamo. Becario en el programa de Formación de Profesorado Universitario por el Ministerio de Educación y Ciencia. Ha participado en diversos proyectos de investigación, muchos de ellos como investigador en la Fundación Doctor Robert.Actualmente es miembro del Grupo de Estudios Sociales de la Ciencia y la Tecnología (GESCIT). Los temas sobre los que trabaja actualmente son la relación que tienen las Tic con los Estudios del Discurso, y la importancia que ejerce el papel de las emociones con el lenguaje. Sobre este último tema, se encuentra realizando su investigación doctoral. 
Cristian López es licenciado en Sociología por la Universidad de Barcelona (España). Actualmente cursa los estudios de doctorado de Psicología Social en la Universidad Autónoma de Barcelona

Javier Romano es licenciado en Sociología por la Universidad de la República (Uruguay). Actualmente cursa los estudios de doctorado de Psicología Social por la Universidad Autónoma de Barcelona.

\section{(C)}

Este texto está protegido por una licencia Creative Commons.

Usted es libre de copiar, distribuir y comunicar públicamente la obra bajo las siguientes condiciones:

Reconocimiento: Debe reconocer y citar al autor original.

No comercial. No puede utilizar esta obra para fines comerciales.

Sin obras derivadas. No se puede alterar, transformar, o generar una obra derivada a partir de esta obra.

\section{$\underline{\text { Resumen de licencia }}$}

$\underline{\text { Texto completo de la licencia }}$ 